Fuller and Woods. HCA Healthcare Journal of Medicine (2021) 2:4

https://doi.org/10.36518/2689-0216.1203

\title{
Education
}

\section{The Science of Learning: Why Learning Theories Matter in Graduate Medical Education}

Jacklyn C. Fuller, PhD, 1,2 Melissa Woods, PsyD

\section{Abstract}

\section{Description}

Learning theories are necessary to help inform teaching strategies and promote successful educational outcomes. Having an in-depth knowledge about learning theories and their applicability to teaching and educating healthcare professionals will help support and promote excellence in medical education. Demonstrating an understanding of effective learning theories in the classroom will benefit both educators and trainees, while supporting a collaborative mentor-mentee relationship.

\section{Keywords}

graduate medical education; learning theories; educational learning theory; motivational learning theory; humanistic learning theory; experiential learning theory; reflective learning theory

\section{"Anyone who stops learning is old, whether at twenty or eighty. Anyone who keeps learning stays young." Henry Ford}

Over the past 18 years, personal observations of some of the approaches clinician-educators utilize to stimulate learning in their classrooms have led to contrasting conclusions. Some educators unequivocally focus on the delivery of goals and objectives with an emphasis on the Accreditation Council for Graduate Medical Education (ACGME) core competencies, whereas others capitalize on practices they learned when they were trainees themselves. While competency-based education and levels of familiarity are significant, they are just not enough to adequately prepare and assess the next generation of physicians.

Given the enormous and dynamic changes graduate medical education has undergone, the time has come for institution and program leaders to be more judicious about aligning their educational framework with projected educational outcomes. Research widely shows educational learning theories are instrumental to the design and implementation of healthcare educational programs.,2 Having in-depth knowledge about learning theories and their applicability to teaching and educating healthcare professionals, including residency trainees, will not only guide program curricula design and teaching strategies but also help to mitigate many of the learning apprehensions experienced in the classroom. Additionally, this knowledge will help to alleviate some of the frustrations clinician-educators express with the learning process and the learning environment.

Medical education leaders, such as Designated Institutional Officials (DIOs), should be more attentive to engaging and eliciting help from educators with expertise in the science of learning and adult learning theories to help clinician-educators develop a deeper understanding of those principles, which are fundamental to the success of transferring knowledge. The ACGME grants the DIO and the Graduate Medical Education Committee (GMEC), which is mostly comprised of program leaders, the authority to manage and oversee institution sponsored ACGME-accredited programs. This charge must extend beyond a zest for program accreditation to a deeper emphasis on key oversight activities, such as faculty

\section{HCA 佔 Healthcare}

www.hcahealthcarejournal.com

(C) 2021 HCA Physician Services, Inc. d/b/a Emerald Medical Education
HCA Healthcare Journal of Medicine 
development. This emphasis will guarantee appropriate training for clinician-educators and better prepare them to utilize adult learning theories effectively to help inform the development of curricula, including learning goals and objectives. It will also help them to employ strategies for delivering the intended goals. Incorporating theoretical perspectives into the trainees' educational experience will lend credence to the acquisition of knowledge, skills and attitudes and, ultimately, improve the trainees' learning experience in the classroom and their performance on specialty board examinations. This article will focus on learning theories relevant to developing curricula and teaching strategies for training learners in graduate medical education.

There is a vast array of theories that are relevant to medical education. This article will focus on the following theories with which those tasked with teaching should be familiar: 1) Foundational educational learning theories, including behaviorist, cognitivist and constructivist theories, 2) Motivational theories that aim to discover what drives an individual to work towards a goal, 3) Humanistic theories that are learner-centered and support self-directed learning, 4) Experiential theories that put knowledge into practice, and 5) Reflective theories that promote building on past experience. The concepts and ideas presented in these theories are essential for helping align educational goals and objectives with better outcomes, and, therefore, better preparing trainees to undertake the practice of medicine competently.

Educational learning theory seeks to describe and better understand how and why learners receive, interpret, process and retain information in the learning process. While there are many learning theories, all have roots in three foundational ones: behaviorism, cognitivism and constructivism. Behaviorism postulates that learning is a change in behavior in a desired direction due to strategies and techniques enforced by the educator and the learning environment. The essence of this theory suggests that learners can be reinforced to produce desired behaviors based on the educators' interaction with the learner. ${ }^{3}$ Behaviorism is an educational model that exemplifies a teacher-centered approach to learning in which the educator develops a learning environment designed to achieve a desired response. This model relies on repetition and reinforcement, and it promotes and emphasizes the value of feedback in the learning environment. Having a working knowledge and understanding of this theory will help medical educators establish and communicate expectations, articulate key learning objectives, as well as practical assessment strategies, and employ behavioral management techniques towards overarching curricular goals.

Cognitivism, in contrast to behaviorism, explores learning through information-processing models with an emphasis on the learner's internal environment. In cognitivist theory, the learner interprets and processes information received rather than eliciting a conditional behavior. From this perspective, learning occurs when an individual mentally processes and reorganizes information through discovery or adaptation of prior knowledge. ${ }^{3}$ Educational learning models grounded in cognitivism promote a teacher-student paradigm in which instruction is designed to capture the learner's attention and create opportunities for the learner to actively participate in the learning process. An understanding of this theory will assist educators in strengthening essential mental processes such as critical thinking, problem-solving, memory and perception.

Constructivism proposes that acquired knowledge is unique to the learner through the construction of new ideas that are based on previous knowledge and experiences. In order for this theory to be effective in an educational setting, the learner must have base knowledge of the material being taught. Educators who understand this theory understand that their students bring unique experiences to the learning environment, which impact how they are able to learn. Consequently, educators need to match the level of their instruction to the learner's level of understanding. ${ }^{3}$

Not understanding these theoretical foundations can lead to the misunderstandings that are prevalent in graduate medical education. For example, when a trainee is consistently unable to demonstrate an understanding of a concept presented in the learning environment, the trainee is most oftentimes identified as 
lacking fundamental medical knowledge and may subsequently have to undergo intervention by way of remediation. While this assessment may be true for some trainees, it may not be the case for others. Preceptors who are trained to recognize and better understand adult learning viewpoints of theory are able to draw upon their knowledge to redirect learning exercises, which assists trainees in reconstructing their conceptual understanding. The ability to transform the trainees' way of thinking is relevant to avoiding gaps in learning.

Motivation is equally important to advance adult learning and is a common strategy that is widely used across institutions, including teaching hospitals, to influence behaviors and outcomes. Motivation can be intrinsic or extrinsic and can be influenced by rewards such as recognition and satisfaction and by avoidance of negative outcomes such as shame or failure. Studies on intrinsic and extrinsic motivation have provided insight into the developmental and educational practices of the learner. ${ }^{4}$ Learners who are intrinsically motivated seek out activities for pure interest and enjoyment. However, learners who are extrinsically motivated only complete activities when there is a desired outcome or reward. ${ }^{4}$ In order to adapt to the different types of learners-those who are motivated by internal or external rewards and others who are driven by both triggerseducators must intentionally develop and implement multifocal motivational strategies that meet the needs of all learners. This strategy will boost engagement and morale in the learning environment and promote targeted interventions to support and drive motivations based on individual learning.

Humanistic learning theory is also relevant to graduate medical education since it emphasizes the importance of educators creating an environment that is conducive to learning. This strategy allows for a holistic approach to learning, and the primary focus should be on the learner. With a key focus on the individualistic needs of the trainee in the learning environment, a holistic approach will engage the trainee and result in self-responsibility for the decisions that will affect the resident's learning. Self-responsibility is an essential component to learning since it emphasizes knowledge and outcomes that are a direct consequence of the learner's choices. A system in which educators intentionally attend to individual needs of the learner, matched with equal efforts from the learner, will foster successful growth and development in the education setting.

Experiential theory is a key initiative to engage trainees in quality improvement activities.

Section VI.A.1.b3 of the ACGME 2020 Common Program Requirements for residency and fellowship states, "Experiential learning is essential to developing the ability to identify and institute sustainable systems-based changes to improve patient care". Given this mandate by the ACGME, it is even more crucial for institutional leaders to ensure faculty-educators receive training on how to promote experience-based learning within real world contexts. Having an in-depth understanding of how to actively engage trainees' learning through doing will empower trainees to apply theoretical knowledge to practical activities in a multitude of settings within the classroom as well as the clinical environment. This fundamental understanding of experiential learning will also inform learning objectives and teaching strategies to help advance trainees' involvement in quality improvement and patient safety as well as their overall learning experiences.

Reflection is useful in helping individuals make sense of unfamiliar situations or events, and repeated reflection can assist learners in building upon previous experiences. In medical education, experiential learning is often utilized through gradual exposure with patient care. In many instances, such strategies promote a form of experiential learning known as episodic learning. Episodic learning is the process of storing information from experiences in one's long-term memory or utilizing that information to improve behavior. Within this type of learning, experiences are often recorded to memory exactly as it was experienced without the content of the experience being modified. Learning in the clinical environment as a whole should be an ongoing process inclusive of equal investment by preceptors and trainees. The principles of reflective theory propose an application of reflection on current and past experiences to better reason and problem-solve unfamiliar events while they are occurring. ${ }^{6}$ In the medical setting, the utilization of reflective theory allows trainees to create a memory 
bank of rehearsed interventions, so that when unexpected situations arise, trainees are better equipped to respond in an instinctive, rapid and accurate manner.

Learning theories are necessary to help inform teaching strategies and promote successful educational outcomes. Having an in-depth knowledge about learning theories will help support and promote excellence in medical education. While detailed application of these theories is beyond the scope of this article, demonstrating an understanding of effective learning theories in the classroom will benefit both educators and trainees while supporting a collaborative mentor-mentee relationship. ${ }^{7}$

\section{Conflicts of Interest}

Jacklyn C. Fuller declares that she has no conflicts of interest.

Melissa Woods declares that as a servicemember of the United States Air Force, the views expressed are those of the authors and do not reflect the official policy or position of the US Air Force, Department of Defense or the US Government.

Jacklyn C. Fuller is an employee of HCA Healthcare Graduate Medical Education, an organization affiliated with the journal's publisher.

This research was supported (in whole or in part) by HCA Healthcare and/or an HCA Healthcare affiliated entity. The views expressed in this publication represent those of the author(s) and do not necessarily represent the official views of HCA Healthcare or any of its affiliated entities.

\section{Author Affiliations}

1. HCA Healthcare, Graduate Medical Education, Brentwood, TN

2. Ocala Health, Ocala, FL

\section{References}

1. Mukhalalati BA, Taylor A. Adult learning theories in context: a quick guide for healthcare professional educators. J Med Educ Curric Dev. 2019;6:2382120519840332. https://doi. org/10.1177/2382120519840332

2. Torre DM, Daley BJ, Sebastian JL, Elnicki DM. Overview of current learning theories for medical educators. Am J Med. 2006;119(10):903-907. https://doi.org/10.1016/j.amjmed.2006.06.037
3. Arghode V, Brieger E, Mclean G. Adult learning theories: implication for online instructions. European Journal of Training and Development. 2017;14(7):593-609. https://eric.ed.gov $\angle ?$ id $=$ EJ1156364

4. Ryan RM, Deci EL. Intrinsic and extrinsic motivations: classic definitions and new directions. Contemp Educ Psychol. 2000;25(1):54-67. https:// doi.org/10.1006/ceps.1999.1020

5. Common Program Requirements (Residency). Accreditation Council of Graduate Medical Education (ACGME). 2020. Accessed August 10, 2021. https://www.acgme.org/Portals/O/PFAssets/ProgramRequirements/CPRResidency2020. pdf

6. Kaufman DM. Applying educational theory in practice. BMJ. 2003;326(7382):213-216. https:// doi.org/10.1136/bmj.326.7382.213

7. Toklu HZ, Fuller JC. Mentor-mentee relationship: a win-win contract in graduate medical education. Cureus. 2017;9(12):e1908. https://www. cureus.com/articles/9919-mentor-mentee-relationship-a-win-win-contract-in-graduate-medical-education 